\title{
Reducing Maternal And Child Health Disparities Among Latino Immigrants In South Carolina Through A Tailored, Culturally Appropriate And Participant- Driven Initiative
}

\author{
Myriam E. Torres, Julie Smithwick, Kathryn J. Luchok, Gwyn Rodman-Rice \\ University of South Carolina
}

\begin{abstract}
Newly arrived Latino immigrants in South Carolina (SC), especially Latina mothers, experience many health related barriers including a general lack of health services information. The PASOs program, which means "steps" in Spanish, uses education, outreach, partnerships and advocacy to empower Latino families to utilize available health care services throughout SC. PASOs is a community-based program conducted by college trained bilingual/bicultural facilitators with the support from community health care workers (promotores de salud). Participants $(n=523)$ were expectant mothers with an average age of 27 $(\mathrm{SD}=6)$ years, mostly from Mexico $(69 \%)$, with an average of $9(\mathrm{SD}=4)$ years of education and $7(\mathrm{SD}=5)$ years living in the US. Repeated measures analyses from pre-test to post-test indicated significant knowledge improvement ( $\mathrm{p}<0.005)$ regarding the importance of prenatal care, signs of preterm delivery, benefits of breastfeeding, and the importance of folic acid intake during periconception. By the end of the course, the majority of the Latinas $(93 \%$; $\mathrm{p}<0.0001)$ were able to name a birth control method they planned to use following their current pregnancy. Results of this study emphasize the benefits associated with the implementation of a culturally-appropriate program with newly arrived Latino immigrants, including an increase on preconception, pregnancy, and post-pregnancy knowledge.
\end{abstract}

(C) 2012 Californian Journal of Health Promotion. All rights reserved.

Keywords: Latino immigrants, maternal and child health, prenatal program, cultural relevancy

\section{Introduction}

Thirty-five percent of South Carolina residents belong to a racial or ethnic minority group (South Carolina Department of Health and Environmental Control [SCDHEC], 2011) and over the past decade the minority population has increased by $18 \%$. Like most southeastern states, South Carolina has experienced rapid growth of its Latino population, which has more than doubled in size between 2000 and 2010, and represents the largest increase in this population among all 50 states (Pew Hispanic Center, 2011).

This dramatic growth has been fueled by high rates of immigration and a fertility rate over $60 \%$ greater than the general population of the United States (McDonald, Suellentrop, Paulozzi,
\& Morrow, 2008). The fertility rate of Latinas in South Carolina is 184 births per 1,000 women aged 15-44, more than double the rate for nonLatina white women (62.1) and non-Latina black women (71.6) (SCDHEC, 2009b).

The purpose of this study was to evaluate the prenatal education component of the PASOs Program, a community based organization designed to address the maternal and child health disparities faced by Latinos in South Carolina by facilitating access to culturally relevant information, resources, and skills. PASOs, which is Spanish for "steps" is tailored specifically to the linguistic and cultural needs of a newly settled Latino immigrant population who have come to South Carolina from various countries, the largest group from rural areas of 
Torres, M.E., Smithwick, J., Luchok, K. J., \& Rodman-Rice, G. / Californian Journal of Health Promotion 2012, Volume 10, Special

Mexico. This study examined whether the specificity and the evaluation feedback loop, both core components of the PASOs prenatal education course, led to significant changes in knowledge, attitudes and practices that could reduce health disparities for this population.

\section{Perinatal Health Disparities Among Latina Women}

Folic Acid And Neural Tube Defects

The Latino population in the United States faces health disparities in several areas that relate to the health and well-being of Latino mothers and children. Latina women have a 1.5 to 3 times higher risk of having a child that is affected with neural tube defects like spina bifida and anencephaly (CDC, 2010). Folic acid taken before and during pregnancy reduces the risk of these birth defects; however, Latinas are more likely to have low blood folate levels, less likely to consume foods fortified with folic acid and less likely than other women to know about the benefits and importance of taking folic acid prior to becoming pregnant (CDC, 2010; Boulet, Yang, Mai, Kirby, Collins, Robbins, Meyer, Canfield \& Mulinare, 2008).

\section{Gestational Diabetes}

Pregnant Latina women have a higher rate of gestational diabetes than non-Latina white and non-Latina black women, $4.9 \%, 3.4 \%$ and $3.2 \%$ respectively (Caughey, Cheng, Stotland, Washington \& Escobar, 2010; McDonald, et al., 2008). Gestational diabetes is one of the most common complications that women suffer from during pregnancy (Baptiste-Roberts, Barone, Gary, Golden, Wilson, Bass \& Nicholson, 2009) and is associated with infant mortality, congenital malformations and complications during labor and delivery (SCDHEC, 2009a).

\section{Early And Adequate Prenatal Care}

Latina women are less likely to receive early and adequate prenatal care than other ethnic groups (McDonald, et al., 2008; Phillipi, 2009). Data for South Carolina averaged during 2006-2008 show Latinas had the highest rates of late or no prenatal care compared to other women (March of Dimes, 2011). The rate of late or no prenatal care for Latinas giving birth in South Carolina $(16.6 \%)$ was more than three times the rate among white women (5.4\%). Across the same time period in South Carolina, Latinas had the lowest rates of adequate/adequate plus prenatal care, $(51.0 \%)$ compared to non-Latina white women $(75.6 \%)$, Asian women (67.9\%), nonLatina black women (66.6\%), and Native American women (64.6\%).

\section{Food-Borne Disease}

Pregnant Latina women have high rates of foodborne disease morbidity and mortality (CDC, 2007). Overall, these diseases cause approximately 76 million illnesses, 325,000 hospitalizations, and 5,000 deaths in the United States each year. Latino food preferences, such as unpasteurized milk products, create a higher risk for food-borne infections that increase the risk of miscarriage among pregnant women (CDC, 2007).

\section{Breastfeeding}

Lower-income Latina women have fairly good rates of breastfeeding initiation $(70 \%)$, but not continuation, with only $30 \%$ breastfeeding at 6 months. Both are below the Healthy People 2020 target goals of $81.9 \%$ and $60.6 \%$ respectively (Bunik, Clark, Zimmer, Jimenez, O'Connor, Crane \& Kemp, 2006; United States Department of Health and Human Services, 2010). A preference for combining bottlefeeding with breastfeeding is associated with these lower rates of continuation (Bunik, et al., 2006).

\section{Infant And Child Safety Disparities}

Minorities and low-income populations generally use seatbelts and child safety seats less often than the general population (Istre, McCoy, Womack, Fanning, Dekat \& Stowe, 2002). One preliminary study conducted in Texas showed that Latinos used child restraints for

preschoolers at a much lower rate than the general population, $19 \%$ vs. $62 \%$ respectively (Istre, et al, 2002). Safe infant sleeping practices are another disparity, with Latino and AfricanAmerican infants significantly less likely to back sleep than non-Latino white infants (BarnesJosiah, Eurek, Huffman, Heusinkvelt, SevereOforah \& Schwalberg, 2007).

\section{Family Planning Disparities}


Family planning rates are lower among Latina women as compared to non-Latina white women, and unplanned pregnancies are higher. Among poor women, Latinas have higher rates of unintended pregnancy than non-Latina black or white women (Finer \& Henshaw, 2001; Grossman, Fernandez, Hopkins Amastae \& Potter, 2010). Contraceptive nonuse and failure are higher among Latinas than other groups, and misinformation about risks of methods is also high (Frost, Sing \& Finer, 2004; Kost, Singh, Vaughn, Trussell \& Bankole, 2008; Grossman et al., 2010).

\section{The Latino Paradox}

Despite lower socioeconomic status and limited access to quality healthcare, foreign-born Latina women generally have better birth outcomes than Latina women born in the United States (McDonald et al., 2008; Collins \& Shay, 1994; Brown, Chireau, Jallah \& Howard, 2007), with this effect being more pronounced for Mexicanborn women than Latina women from other countries (Acevedo-Garcia, Soobader $\&$ Berkman, 2007). One explanation posits that the healthiest Latinas immigrate to the United States, translating into more positive birth outcomes (Landale, Oropesa \& Gorman, 2000). They carry with them culturally approved health promoting behaviors such as less tobacco and drug use during pregnancy, which can reduce the risk of having a low birth weight baby (McDonald et al., 2008). Strong social support networks that affirm mothers are also commonly found among Latino populations (McDonald et al., 2008), but these ties may be interrupted by immigration.

Sociocultural protective factors that lead to positive birth outcomes among newly immigrated Latinas appear to erode in subsequent generations (Collins \& Shay, 1994; Brown, et al., 2007). In general, as duration in the U.S. increases, Latino immigrants do worse on a variety of health outcomes (Abraído-Lanza, Chao \& Flórez, 2005; Acevedo-Garcia, Bates, Osypuk \& McArdle, 2010; Cho, Frisbie \& Rogers, 2004).

\section{Background Of The Development Of PASOs In South Carolina}

It is clear that Latino immigrants face some particular health challenges, and these come into sharp focus in localities that experience rapid growth of this population. In 2004, noting the growing Latino population in the central region of South Carolina, a study of maternal and child health needs was conducted that showed that Latina women have limited access to and information about resources, putting them at risk for poorer birth outcomes (Smithwick-Leone, 2005). In response to these findings, the PASOs Prenatal Program was founded in 2005 with a small grant from the South Carolina Chapter of the March of Dimes. PASOs began to fill gaps faced by the Latino immigrant population and liaise between this population and health care providers, hospital systems, and maternal child health coalitions in areas of high population growth. As a result, there was increased demand to expand the program around the state. Currently PASOs offers services in 13 counties in diverse regions of the state, including the five South Carolina counties with the highest percentage of Latinos (United States Census Bureau, 2010).

\section{Best Practices Employed By The PASOs Prenatal Program}

The PASOs Prenatal Program combines prenatal education, resource navigation, community outreach, system advocacy and leadership development of community health workers. The prenatal curriculum and materials are culturally appropriate and tailored to the Latino population of South Carolina, while also respecting and responding to diversity within this population. In March 2011, PASOs was named "A Promising Practice" by the Association of Maternal and Child Health Programs (AMCHP) and was awarded the "Promising Practice of the Year" by AMCHP in February 2012.

Culturally And Linguistically Appropriate Prenatal Education

Central to the PASOs Prenatal Program is the 14-hour prenatal course for Latino families in Spanish. The importance of prenatal classes is widely encouraged and supported throughout the medical and public health fields (Best Start: Ontario's Maternal, Newborn and Early Child Development 
Resource Centre, 2007; Philipsen, 2004). One study showed that women who attended prenatal classes had a much lower risk of cesarean section, were about half as likely to bottle-feed and received better information on contraception, breastfeeding and baby care (Spinelli, Baglio, Donati, Grandolfo \& Osborn, 2003). The Public Health Service Expert Panel recommendations for the content of prenatal care included seven areas on which pregnant women should receive advice including: breastfeeding; reducing or eliminating alcohol use; reducing or eliminating smoking; not using illegal drugs; eating the proper foods during pregnancy; taking vitamin or mineral supplements; and appropriate amount of weight gain during pregnancy (Sable \& Herman, 1997). Each of these topics is included in the PASOs prenatal course objectives, and is tailored to the needs that have been identified through a continual feedback loop with PASOs' target population.

Many of PASOs' participants are either first time mothers or women having a child for the first time in the U.S. Many have lost traditional support networks that would traditionally teach them positive behaviors. PASOs is designed to reinforce the positive behaviors individuals have brought with them, teach ways to put these behaviors into practice in their new environment, build new supportive relationships, and facilitate learning and adopting of new information.

\section{Curriculum And Educational Materials}

PASOs educational materials are consistently evaluated for accuracy, cultural sensitivity and appropriateness of the reading level for the target audience. Initially, PASOs delivered education using a March of Dimes program entitled Comenzando Bien ("Starting off well" in

English), since there was no appropriate model developed with the Latino community in the southeastern United States (March of Dimes, 2004). Through participant feedback and evaluation, PASOs has developed a new curriculum that incorporates components from Comenzando Bien, other curricula, and original elements.

Incorporation of diverse perspectives

Although there is much diversity among Latino cultures, there are some common cultural values such as familismo, personalismo, respeto, and confianza, that have been identified and incorporated into the PASOs curriculum (Wasserman, Bender \& Lee, 2007), among others. All efforts are made to maintain the fidelity of the PASOs curriculum and the instruction methods, while also allowing for flexibility based on the participants in any given course. Program coordinators are trained to assess the diversity of participants in each course through intake demographic information and initial conversations to determine how to best tailor the course. Information taken into account includes country of origin, education level, previous pregnancies and level of experience. Program coordinators also use various terminologies during educational interventions to incorporate diversity of dialects. Each activity in the curriculum is designed to first gather input from the participants about their knowledge and experiences, and once this information is provided, facilitate information sharing.

\section{Bilingual And Bicultural Staff}

The inability to understand and communicate with healthcare professionals is a dramatic barrier that may limit care. PASOs has identified this barrier and incorporated a staff that is entirely bilingual and bicultural, and majority Latino. Having such a staff allows the organization to better communicate with the target audience and provide information in a culturally competent way. PASOs incorporates the Latino perspective at each level of the organizational structure, including program coordination, community partnerships, regional

boards for each of the programs, and the state advisory board.

Emphasis On The Importance Of Community Health Workers 
The World Health Organization's (WHO) 1978 Declaration of Alma-Ata stated that one of the key strategies for achieving optimum health is to have basic health services delivered by community health workers (World Health Organization, 1978). This idea is still very relevant today in the United States, where despite technology and resources, there are still many disparities and impediments to accessing quality healthcare services. Community health workers provide a culturally sensitive way to bridge gaps between the healthcare system and isolated communities (Meister, Warrick, de Zapién \& Wood, 1992). By preparing community health workers, involving the community in forming programs, and organizing the internal structure of the organization, PASOs embodies the World Health Organization's idea that people have the right and duty to participate individually and collectively in the planning and implementation of their own healthcare (WHO, 1978). The PASOs program's use of community health workers helps strengthen existing support networks and, in some cases, rebuilds traditional support networks. Community health workers are involved in evaluating the PASOs Prenatal Program and in co-facilitating the educational courses.

\section{Purpose Of The Study}

The purpose of this study was to examine what impact the PASOs Prenatal Program's 14-hour prenatal education course has had on participants' knowledge and self-reported behaviors surrounding maternal and child health and whether this community-based practice approach would yield a socioculturally appropriate program for perinatal health for Latino immigrants in South Carolina.

\section{Methods}

\section{Study Design And Data Collection}

Central to the evaluation of the PASOs prenatal education course is an intervention study using a pretest and posttest model to determine the impact of the 14-hour course. The tests are administered interview-style in Spanish to assure that the participants understand the questions and to accommodate those who are not able to read. Women who fail to take the pretest at the beginning of the course are able to complete the socio-demographic portion of the pretest when they complete the posttest. The study received approval by the Institutional Review Board (IRB) from the University of South Carolina.

\section{Sample Size}

The data included in this study is of the PASOs prenatal education evaluation tool, which was administered to all Latina women (523) attending the courses between 2007-2010 from 13 counties (Beaufort, Berkeley, Clarendon, Charleston, Dorchester, Edgefield, Greenville, Jasper, Lexington, Newberry, Richland, Saluda, and Williamsburg) of South Carolina.

\section{Measures}

The pretest included broad demographics, such as age, place of birth (country and state), place of residence, years residing in the U.S., level of education, number of pregnancies, total number of children, and number of children younger than five. In addition, the demographic profile included questions about access to health insurance, participation in the Women, Infants and Children (WIC) program, participants' plans to apply for WIC during the current pregnancy, intention to apply for Medicaid or Emergency Medicaid to cover costs of prenatal care or labor and delivery, and knowledge of necessary documents to effectively solicit Medicaid coverage (for those who would be applying). Data was also collected on the time when participants became aware of the pregnancy and when the first prenatal visit occurred.

Tables 3 and 4 show the pretest and posttest results related to knowledge. Much of the data in these sections were collected using open-ended questions that were coded individually and then grouped by one of the researchers as "correct" or "incorrect" based on scientific evidence.

"Incorrect" was also assigned when participants were asked a question and did not provide an answer.

The knowledge and behavior section of the instrument included questions related to risk behaviors during pregnancy, pregnancy complications, diet, infant care and safety, postpartum care, and family planning (Tables 3 
and 4). For quality control and to measure intention to change specific behaviors, the tool included questions about instructional methodologies and specific changes participants planned to incorporate into their lifestyles.

\section{Data Management And Statistical Analysis}

One of the researchers created a database using EpiData 3.1 software (Lauritsen \& Bruus, 20032005) and exported the data to SAS 9.2 (SAS 9.2 SAS Institute Inc., 2011) for statistical analysis. Data are presented using descriptive statistics including percentages for categorical variables. Open-ended questions were coded as " 1 " if the answer was "correct" and " 0 " if the answer was "incorrect". Since most participants listed more than one answer, the evaluator calculated means of correct and incorrect answers. To calculate significant differences between pretest and posttest scores, multiple logistic regression models adjusted by demographic variables were used when comparing categorical variables, and paired sample t-tests when comparing means. If the $p$ value was 0.05 or less, the differences were considered to be statistically significant.

\section{Results}

\section{Sample Size}

Five hundred twenty-three (523) pregnant Latina women were administered the PASOs prenatal course evaluation tool between 2007 and 2010 . Of this group, $514(98.3 \%)$ answered the pretest and $355(67.9 \%)$ answered the posttest. A total of 346 participants $(66.2 \%)$ completed both the pretest and posttest. Most participants in the educational course who did not complete the posttest were unable to do so because they gave birth before completing the course or had insurmountable logistical barriers (Franco, personal communication, 2011). Statistical analyses indicated that those who completed both the pretest and the posttest and those who completed only the pretest were not significantly different with respect to demographic characteristics.

\section{Socio-Demographic Characteristics}

Table 1 shows that the majority $(63.7 \%)$ of the participants were between the ages of 20 and 30 years old, with one participant as young as 14 . More than two-thirds were originally from Mexico and of those, the highest percentages hailed from the states of Veracruz $(16.9 \%)$ and Oaxaca $(14.6 \%)$ (data not shown in table).

Table 1

PASOs Participants

Selected Social And Demographic Information $(n=523)$

\begin{tabular}{|c|c|c|}
\hline Characteristic & $\mathrm{n}$ & $\%$ \\
\hline \multicolumn{3}{|l|}{ Age } \\
\hline Younger than $20^{1}$ & 55 & 10.7 \\
\hline $20-25$ & 174 & 33.9 \\
\hline $26-30$ & 153 & 29.8 \\
\hline $31-35$ & 95 & 18.5 \\
\hline Older than 35 & 37 & 7.2 \\
\hline Missing & 9 & - \\
\hline \multicolumn{3}{|l|}{ Country of Birth } \\
\hline Mexico & 354 & 68.9 \\
\hline Guatemala & 61 & 11.9 \\
\hline Honduras & 32 & 6.2 \\
\hline Colombia & 23 & 4.9 \\
\hline U.S. & 13 & 4.5 \\
\hline Other $^{2}$ & 31 & 2.5 \\
\hline Missing & 9 & - \\
\hline \multicolumn{3}{|c|}{ Years living in the United States } \\
\hline Less than 5 years & 170 & 40.8 \\
\hline $5-9$ years & 155 & 37.2 \\
\hline 10 years or more & 92 & 22.1 \\
\hline \multicolumn{3}{|l|}{ Years of Education } \\
\hline Less than high school & 317 & 62.8 \\
\hline High school graduate & 112 & 22.2 \\
\hline Some college or more & 76 & 15.1 \\
\hline Missing & 18 & - \\
\hline \multicolumn{3}{|l|}{ Health Insurance } \\
\hline Yes & 43 & 8.4 \\
\hline No & 470 & 91.6 \\
\hline Missing & 10 & - \\
\hline
\end{tabular}

Approximately $80 \%$ of participants reported living in the U.S. for less than 10 years and almost two-thirds (62.8\%) reported an educational attainment of less than high school. Half of the participants reported an annual household income of $\$ 15,600$ or less and about $92 \%$ reported not having any health insurance.

Table 2

PASOs Participants

Past And Current Pregnancy And Prenatal Care (n=523)

\begin{tabular}{lll} 
Characteristic & $\mathrm{n}$ & $\%$ \\
\hline
\end{tabular}

Previous prenatal education 


\begin{tabular}{|c|c|c|}
\hline Yes & 65 & 14.2 \\
\hline No & 393 & 85.8 \\
\hline Missing & 65 & 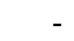 \\
\hline \multicolumn{3}{|l|}{ Previous pregnancy } \\
\hline Yes & 361 & 78.0 \\
\hline No & 102 & 22.0 \\
\hline Missing & 60 & - \\
\hline \multicolumn{3}{|c|}{$\begin{array}{l}\text { Number of previous pregnancies } \\
\text { (of those with previous } \\
\text { pregnancies) }\end{array}$} \\
\hline One & 137 & 38.0 \\
\hline Two & 105 & 29.1 \\
\hline Three & 71 & 19.7 \\
\hline Four or more & 48 & 13.3 \\
\hline \multicolumn{3}{|l|}{ Number of children } \\
\hline No children & 43 & 12.5 \\
\hline One child & 149 & 43.3 \\
\hline Two children & 90 & 26.2 \\
\hline Three children & 42 & 12.2 \\
\hline Four children and more & 20 & 5.8 \\
\hline \multicolumn{3}{|l|}{$\begin{array}{l}\text { Children younger than } 5 \text { (from } \\
\text { those who have children) }\end{array}$} \\
\hline Yes & 170 & 67.2 \\
\hline No & 83 & 32.8 \\
\hline \multicolumn{3}{|c|}{$\begin{array}{l}\text { Trimester when aware of current } \\
\text { pregnancy }\end{array}$} \\
\hline First & 425 & 85.5 \\
\hline Second & 69 & 13.9 \\
\hline Third & 3 & 0.6 \\
\hline Missing & 26 & 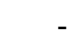 \\
\hline \multicolumn{3}{|l|}{ Trimester of first prenatal visit } \\
\hline First & 279 & 58.6 \\
\hline Second & 187 & 39.3 \\
\hline Third & 10 & 2.1 \\
\hline Missing & 47 & 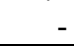 \\
\hline
\end{tabular}

\section{History Of Pregnancy And Current Prenatal Care}

Even though most of the women reported a previous pregnancy $(78 \%$ ) (see table 2$)$, the vast majority $(85.8 \%)$ stated they had not received any form of prenatal education before. Of the women who reported previous pregnancies, the majority $(38 \%)$ had only been pregnant once before, and among all participants, $43 \%$ stated they had only one child. In commenting on their current pregnancies at the time of enrollment in the PASOs Prenatal Program, $85.5 \%$ of women reported becoming aware of their pregnancy during the first trimester, but only about 59\% started their prenatal care during that time. At the time of enrollment into the program, if a participant was not attending prenatal care appointments, the program coordinators made every effort to get the participant enrolled and assist her in finding ways to overcome logistical barriers to care.

\section{Acquired Knowledge After The PASOs Course}

As shown in Table 3, participants experienced statistically significant knowledge gains between the pretest and posttest measurement points. Although there were many areas of improvement in knowledge, the greatest gains were observed in questions related to safe sleep practices (from mean correct answers in pretest of 1.1 to a mean of 2.2 correct answers in posttest; $\mathrm{p}<0.05$ ) and Shaken Baby Syndrome (from mean correct answers in pretest of 0.6 to a mean of 1.6 correct answers in posttest; $p<0.05$ ).

Table 4 shows that, consistently, the participants acquired knowledge on many of the topics covered in the curriculum. Participants learned the importance of taking folic acid $(54 \%$ at pretest to $91 \%$ at posttest; $p=0.0005$ ) at the most adequate time to protect against neural tube defects $(50 \%$ at pretest to $87 \%$ at posttest; $\mathrm{p}=0.0004$ ), as well as the significance of iron intake during pregnancy (26\% at pretest to $80 \%$ at posttest; $p=0.0019$ ). Additionally, participants gained knowledge about normal "mood changes" at postpartum ( $56 \%$ at pretest to $89 \%$ at posttest; $\mathrm{p}=0.0032$ ); however, researchers were not able to detect any statistically significant improvement in differentiating between signs of the more common "baby blues" and postpartum depression.

\section{Behavior Change And Intentions To Change Behaviors}

Table 5 displays several variables measuring actual behavior change and intentionality of changing behaviors. Having acquired WIC benefits increased at a statistically significantly

Table 3 
Torres, M.E., Smithwick, J., Luchok, K. J., \& Rodman-Rice, G. / Californian Journal of Health Promotion 2012, Volume 10, Special Issue: Health Disparities in Latino Communities, 1-14

\begin{tabular}{|c|c|c|c|c|}
\hline Variable & $\begin{array}{l}\text { Pretest } \\
\text { Mean* }\end{array}$ & $\begin{array}{l}\text { Posttest } \\
\text { Mean }\end{array}$ & $\begin{array}{l}\text { Mean } \\
\text { Difference }\end{array}$ & P-value \\
\hline $\begin{array}{l}\text { 1. Understanding that early and regular prenatal care can help } \\
\text { prevent problems during pregnancy }(\mathrm{n}=396)\end{array}$ & 0.4 & 0.5 & +0.1 & $<0.05$ \\
\hline 2. Knowledge of warning signs during pregnancy $(n=395)$ & 1.1 & 1.8 & +0.6 & $<0.05$ \\
\hline $\begin{array}{l}\text { 3. Knowledge that unpasteurized cheese can lead to food borne } \\
\text { illnesses during pregnancy }(n=329)\end{array}$ & 0.2 & 1.0 & +0.8 & $<0.05$ \\
\hline $\begin{array}{l}\text { 4. Knowledge of risk of food-borne illnesses during pregnancy } \\
\text { from consumption of unpasteurized cheese }(n=393)\end{array}$ & 0.1 & 1.0 & +0.8 & $<0.05$ \\
\hline 5. Knowledge of anesthesia options for delivery $(n=333)$ & 0.5 & 0.9 & +0.4 & $<0.05$ \\
\hline 6. Knowledge of benefits of breastfeeding for mother $(n=396)$ & 0.6 & 1.6 & +1.0 & $<0.05$ \\
\hline 7. Knowledge of benefits of breastfeeding for baby $(n=396)$ & 1.4 & 2.2 & +0.8 & $<0.05$ \\
\hline $\begin{array}{l}\text { 8. Knowledge of birth control options during lactation period } \\
(\mathrm{n}=261)\end{array}$ & 0.3 & 1.0 & +0.7 & $<0.05$ \\
\hline 9. Knowledge of safe sleep measures $(n=396)$ & 1.1 & 2.2 & +1.1 & $<0.05$ \\
\hline 10. Knowledge of effects of Shaken Baby Syndrome $(n=396)$ & 0.6 & 1.6 & +1.1 & $<0.05$ \\
\hline
\end{tabular}

percentage $(37.1 \%$ at pretest to $39 \%$ at posttest for a total of $76.5 \%$ with WIC; $\mathrm{p}<0.0001)$. Use of a multivitamin with folic acid showed a statistically significantly increase as well $(75 \%$ pretest to $96 \%$ posttest; $\mathrm{p}=0.00127)$. Additionally, a statistically significant higher proportion of women reported they would breastfeed their infants after the course $(39 \%$ at pretest to $61 \%$ at posttest; $p=0.0004$ ) and, consequently, a lower number of women would bottle-feed. Similarly, a statistically significant larger number of women described their intention to use a specific and named birth control method $(77 \%$ at pretest to $93 \%$ at posttest; $p<0.0001$ ) after giving birth.

Almost every participant (98.7\%) reported she would make a positive change after attending the PASOs course; more than half $(55.1 \%)$ stating this change involved ways to better care for their infants. About 27\% said they would make changes to help them have healthier pregnancies and others mentioned changes related to the birth process $(5.5 \%)$, aspects related to women's health $(5.1 \%)$ and changes related to a heightened sense of empowerment $(4.5 \%)$.

\section{Discussion}

\section{Summary Of The Findings}

The pregnant Latina women who participated in the PASOs prenatal education course were young, had low levels of education and income and most lacked health insurance, all characteristics that put them at risk for potential negative maternal and child health incomes. Additionally, participants were accessing prenatal care later than advisable and had not received prenatal education elsewhere. These disparities in health care services and resources were addressed through the PASOs Prenatal Program. By attending the 14-hour prenatal education course, this underserved population of new immigrants acquired a great deal of knowledge about how to have healthy pregnancies and effectively care for their infants

Table 4 
Torres, M.E., Smithwick, J., Luchok, K. J., \& Rodman-Rice, G. / Californian Journal of Health Promotion 2012, Volume 10, Special Issue: Health Disparities in Latino Communities, 1-14

Signs Of Delivery, Comprehension Of Healthy Pregnancy Behaviors, And Understanding Of Adequate Nutritional Intake And Perinatal Mood Disorders ( $\mathrm{n}=523)$

\begin{tabular}{|c|c|c|c|c|c|}
\hline \multirow[t]{2}{*}{ Characteristic } & \multicolumn{2}{|c|}{ Pretest } & \multicolumn{2}{|c|}{ Posttest } & \multirow[t]{2}{*}{ p-value } \\
\hline & $\mathrm{n}$ & $\%$ & $\mathrm{n}$ & $\%$ & \\
\hline \multicolumn{6}{|c|}{ Knowledge of need to take folic acid to prevent NTDs } \\
\hline \multicolumn{6}{|c|}{ Correct } \\
\hline Incorrect & 278 & 54.1 & 368 & 91.1 & 0.0005 \\
\hline \multirow[t]{2}{*}{ Missing } & 236 & 45.9 & 26 & 8.9 & \\
\hline & 9 & - & 99 & - & \\
\hline \multicolumn{6}{|c|}{$\begin{array}{l}\text { Knowledge of recommended time to begin taking folic } \\
\operatorname{acid}^{1}\end{array}$} \\
\hline Correct & 183 & 50.1 & 278 & 87.1 & 0.0004 \\
\hline Incorrect & 182 & 49.9 & 41 & 12.9 & \\
\hline Missing & 158 & - & 204 & - & \\
\hline \multicolumn{6}{|l|}{ Knowledge of food with higher iron content ${ }^{1}$} \\
\hline Correct & 93 & 25.5 & 254 & 79.6 & 0.0019 \\
\hline Incorrect & 271 & 74.5 & 65 & 20.4 & \\
\hline Missing & 159 & - & 204 & - & \\
\hline \multicolumn{6}{|l|}{ Knowledge of dilation concept and measurement } \\
\hline \multicolumn{6}{|l|}{ Correct } \\
\hline Incorrect & 298 & 58.1 & 395 & 97.8 & $>0.05$ \\
\hline \multirow[t]{2}{*}{ Missing } & 215 & 41.9 & 9 & 2.2 & \\
\hline & 10 & - & 98 & - & \\
\hline \multicolumn{6}{|l|}{ Knowledge of fetal kick count measure ${ }^{1}$} \\
\hline Correct & 74 & 21.3 & 242 & 85.8 & $>0.05$ \\
\hline Incorrect & 274 & 78.7 & 40 & 14.2 & \\
\hline Missing & 175 & - & 241 & - & \\
\hline \multicolumn{6}{|c|}{$\begin{array}{l}\text { Knowledge of normal mood changes in the postpartum } \\
\text { period }\end{array}$} \\
\hline Yes & 219 & 55.6 & 345 & 87.6 & 0.0032 \\
\hline No & 175 & 44.4 & 49 & 12.4 & \\
\hline Don't Know/NA/Sometimes/Missing & 129 & - & 157 & - & \\
\hline \multicolumn{6}{|c|}{$\begin{array}{l}\text { Differentiation between time period for baby blues and } \\
\text { potential postpartum depression (those who said mode } \\
\text { changes after delivery are normal) }\end{array}$} \\
\hline Correct & 65 & 30.2 & 325 & 94.2 & $>0.05$ \\
\hline Incorrect & 150 & 69.8 & 20 & 5.8 & \\
\hline Missing/Question not asked & 4 & - & 0 & - & \\
\hline
\end{tabular}

*Multiple logistic regression models adjusted by age, education and income

${ }^{1}$ Question introduced later in evaluation process

in their new living environment. Furthermore the evaluation found improvements in participants' intentions to change potentially atrisk behaviors, which may lead to healthier pregnancies and children, and thus reduce disparities in a variety of areas.

There were strong and significant gains in knowledge for PASOs participants in many areas where health disparities exist. For example, participants gained significant knowledge about folic acid and reported increasing their folic acid intake to help prevent neural tube defects that are very prevalent among Latinos in the U.S. (CDC, 2010). Likewise, program participants learned how to prevent common food-borne infections that disproportionately affect Latinas in the U.S.

Table 5 
Torres, M.E., Smithwick, J., Luchok, K. J., \& Rodman-Rice, G. / Californian Journal of Health Promotion 2012, Volume 10, Special Issue: Health Disparities in Latino Communities, 1-14

Behavior Change And Intentions To Change Behaviors As A Result Of The PASOs Prenatal Course

\begin{tabular}{|c|c|c|c|c|c|}
\hline \multirow[t]{2}{*}{ Characteristic } & \multicolumn{2}{|c|}{ Pretest } & \multicolumn{2}{|c|}{ Posttest } & \multirow[t]{2}{*}{ p-value* } \\
\hline & No & $\%$ & No & $\%$ & \\
\hline \multicolumn{6}{|l|}{ WIC current participation } \\
\hline Yes & 280 & 62.9 & 303 & 76.5 & $<0.0001$ \\
\hline No & 165 & 37.1 & 93 & 23.5 & \\
\hline Missing & 78 & - & 127 & - & \\
\hline \multicolumn{6}{|c|}{ Plan to apply to WIC (among those who said no above) } \\
\hline Yes & 121 & 75.2 & 72 & 79.1 & 0.0035 \\
\hline No & 16 & 9.9 & 16 & 17.6 & \\
\hline Don't know & 24 & 14.9 & 3 & 3.3 & \\
\hline Missing & 4 & - & 2 & - & \\
\hline \multicolumn{6}{|l|}{ Daily intake of multivitamin with folic acid } \\
\hline Yes & 385 & 74.9 & 385 & 95.5 & 0.0127 \\
\hline No/Sometimes & 129 & 25.1 & 18 & 4.5 & \\
\hline Missing & 9 & - & 120 & 0.0 & \\
\hline & & & & - & \\
\hline \multicolumn{6}{|l|}{ Newborn feeding intention } \\
\hline Bottle with formula & 23 & 5.0 & 5 & 1.2 & 0.0004 \\
\hline Breastfeeding & 177 & 38.7 & 246 & 61.2 & \\
\hline Breast and bottle with formula & 257 & 56.1 & 151 & 37.6 & \\
\hline Don't know & 1 & 0.2 & 0 & 0.0 & \\
\hline Missing & 65 & - & 121 & - & \\
\hline \multicolumn{6}{|c|}{ Name the birth control method plans to use after this pregnancy } \\
\hline Yes & 315 & 77.4 & 398 & 93.4 & $<0.0001$ \\
\hline No & 92 & 22.6 & 28 & 6.6 & \\
\hline \multicolumn{6}{|c|}{$\begin{array}{l}\text { Whether participants learned something that will help them make a } \\
\text { positive change }\end{array}$} \\
\hline Yes & & & 393 & 98.7 & $<0.0001$ \\
\hline No & & & 5 & 1.3 & \\
\hline Missing & & & 125 & - & \\
\hline \multicolumn{6}{|c|}{$\begin{array}{l}\text { Topic that participants learned that will help them make a positive } \\
\text { change (those who answered yes to previous question) }{ }^{1}\end{array}$} \\
\hline Related to baby care & & & 344 & 55.1 & \\
\hline Ways to have a healthier pregnancy & & & 166 & 26.6 & \\
\hline Related to birth process & & & 34 & 5.5 & \\
\hline Related to woman's health & & & 32 & 5.1 & \\
\hline Related to empowerment & & & 28 & 4.5 & \\
\hline Other & & & 14 & 2.2 & \\
\hline Everything & & & 6 & 1.0 & \\
\hline
\end{tabular}

"Multiple logistic regression models adjusted by age, education and income

${ }^{1}$ Question asked in posttest only. Participants could provide more than 1 answer.

(CDC, 2007) and gained understanding on the importance of prenatal care. They also showed strong gains in understanding family planning and significantly increased their intention to use a specific, named birth control method which could reduce the number of unintended pregnancies. Other significant intentions to change behaviors were related to infant care and safety, such as the intention to breastfeed exclusively and measures to reduce the possibility of infant death due to unsafe sleeping practices.

\section{Limitations}

Some of the limitations of the study included having no comparison group and lack of some posttest data. Only about $66 \%$ of participants responded to both the pretest and posttest, allowing the research team to examine only 
paired gains in knowledge and changes in intentions to alter behaviors. However, upon analysis of differences, researchers found that participants who completed only the pretest were not different from those who participated in both the pretest and the posttest.

Without a comparison group, we could not discern what gains in knowledge immigrant women not attending the classes were obtaining on their own. Furthermore, without a comparison group, it was hard to determine what changes were the results of the intervention rather than due to other factors such as acculturation.

As Latina women acclimate to South Carolina, they may gain similar knowledge as PASOs participants, but it appears unlikely this information is accessible outside of PASOs, based on the percentage of participants who had previous children in the U.S. yet had not received any form of prenatal education. It is also possible that the information participants might have received previously was not presented in a way that met their needs. However, based on the pre-posttest results, the specificity of the PASOs model, with content derived from the requirements of the participants, and classes taught by bilingual and bicultural facilitators, may have been more relevant to participants, and thus better able to meet their needs.

Moreover, the long-term retention of knowledge and behavior change, along with improvements in health outcomes, has not yet been measured. Finally, most of our measurements were related to knowledge gain or intention to change behaviors; but not actual long-term behavior changes. A follow-up process has been initiated which will combine self-reports of longer-term behavior changes and a birth outcomes comparison.

\section{Implications Of The Study}

Many health education programs do not effectively reach their target population due to insufficient knowledge of the intended recipient group and failure to consistently review results and make adjustments to the model and/or educational curriculum. Programs targeted at a generalized Latino population often fail because the programs do not recognize the diversity of the Latino population across the United States. Variations need to be considered, such as whether an immigrant population is settled or newly arrived. Many programs lack the specificity that is needed to address the cultural and structural characteristics of a particular population (Alcalay, et al., 1999).

All elements of the PASOs Program have been developed not only for the new Latino immigrant population in South Carolina, but also with the population, taking into account specific challenges, such as unfamiliarity with health systems navigation and challenges in advocating for health needs, and also building on strengths such as traditional diets and desire to breastfeed. PASOs has built its program model though use of evidenced-based standards, and by ongoing research and feedback-gathering from the Latino community it serves. The combination of culturally and linguistically appropriate educational curricula and materials; incorporation of diverse perspectives; bilingual and bicultural staff; training of community health educators and continuous and comprehensive evaluation makes the program and the education provided easily accessible and relevant, and therefore easily understood and adopted.

This study adds to the literature on communitybased practice, showing how making true efforts to get to know a community, their needs, and their unique qualities, while incorporating their input along the way, can lead to better designed interventions (Wieland, Weis, Palmer, Goodson, Loth, Omer, Abbenyti, Krucker, Edens, \& Sia, 2012; Alcalay, Avarado, Balcazar, Newman, \& Huera, 1999). It also points to the need to press health education beyond the "one size fits all" approach in program planning.

The methods and materials used for the PASOs Prenatal Program may be useful for programs in other states that seek to reduce health disparities among newly arrived and similar Latino populations. In addition, the techniques around specificity of intervention, community 
Torres, M.E., Smithwick, J., Luchok, K. J., \& Rodman-Rice, G. / Californian Journal of Health Promotion 2012, Volume 10, Special Issue: Health Disparities in Latino Communities, 1-14

engagement and iterative feedback can be adapted and replicated in many other settings with many different populations.

For immigrants, navigating a new culture and health care system and obtaining helpful information to maintain health and prevent problems can be a daunting task. PASOs provides support which adds to strengths and knowledge, reinforces positive behaviors and teaches new information and behaviors that can make the navigation process more feasible. While health disparities persist, they can be lessened by programs such as PASOs that empower women to continue relying on their strengths, connect to positive support systems, navigate the health system and have the tools they need to best take care of themselves and their families.

ReferencesAbraído-Lanza, A.F, Chao, M.T. \& Flórez, K.R. (2005). Do healthy behaviors decline with greater acculturation? Implications for the Latino mortality paradox. Social Science and Medicine, $61(6), 1243-1255$.

Acevedo-Garcia, D., Bates, L.M., Osypuk, ${ }^{2}$ T.L \& McArdle, ${ }^{2}$ N. (2010). The effect of immigrant generation and duration on self-rated health among U.S. adults 2003-2007. Social Science \& Medicine 71, 1161-1172.

Acevedo-Garcia, D., Soobader M. \& Berkman, L.F. (2007). Low birthweight among U.S. Hispanic/Latino subgroups: The effect of maternal foreign-born status and education. Social Science and Medicine, 65 (12), 2503-2516.

Alcalay, R., Alvarado, M., Balcazar, H., Newman, E. \& Huerta, E. (1999). Salud Para Su Corazon: A community-based Latino cardiovascular disease prevention and outreach model. Journal of Community Health, 24 (5), 359-379.

Baptiste-Roberts, K., Barone, B., Gary, T.L., Golden, S.H., Wilson, L.M., Bass, E.B. \& Nicholson, W.K. (2009). Risk factors for type 2 diabetes among women with gestational diabetes: A Systematic review. The American Journal of Medicine, 122, 207-214.

Barnes-Josiah DL, Eurek P, Huffman S, Heusinkvelt J, Severe-Oforah J \& Schwalberg R. (2007). Effect of "this side up" T-shirts on infant sleep position. Maternal Child Health Journal, 11 (1), 45-8.

Best Start: Ontario's Maternal, Newborn and Early Child Development Resource Centre (2007). Prenatal education in Ontario: Better practices. Retrieved February 1, 2011 from http://www.beststart.org/resources/rep_health/pdf/prenatal_education_web.pdf.

Boulet, S., Yang, Q., Mai, C., Kirby, R., Collins, J., Robbins, J., Meyer, R., Canfield, M. \& Mulinare, J. (2008). Trends in the post fortification prevalence of spina bifida and ancephaly in the United States. Birth Defects Research, 82, 527-532.

Brown, H.L., Chireau, M.V., Jallah, Y. \& Howard, D. (2007) The "Hispanic paradox": an investigation of racial disparity in pregnancy outcomes at a tertiary care medical center. American Journal of Obstetrics and Gynecology, 197 (2), 197.e1-197.e9

Bunik, M., Clark, L., Zimmer, L.M., Jimenez, L.M., O’Connor, M.E., Crane, L.A. \& Kemp, A. (2006). Early infant feeding decisions in low income Latinas. Breastfeeding Medicine, 1 (4), 225-235.

Caughey, A., Cheng, Y., Stotland, N., Washington, E. \& Escobar, G. (2010). Maternal and paternal race/ethnicity are both associated with gestational diabetes. American Journal of Obstetrics \& Gynecology, 202, 616.e1-5. Retrieved February 1, 2011 from http://www.ncbi.nlm.nih.gov.pallas2.tcl.sc.edu/pubmed/20400060.

Centers for Disease Control and Prevention (2007). Preventing food-borne diseases among pregnant Hispanic Women. Retrieved May 30, 2011 from http://www.cdc.gov/omhd/Populations/HL/HHP/Food.htm

Centers for Disease Control and Prevention (2009). Health, United States, 2009 with special feature on medical technology. Retrieved December 14, 2010 from http://www.cdc.gov/nchs/data/hus/hus09.pdf. 
Torres, M.E., Smithwick, J., Luchok, K. J., \& Rodman-Rice, G. / Californian Journal of Health Promotion 2012, Volume 10, Special Issue: Health Disparities in Latino Communities, 1-14

Centers for Disease Control and Prevention (2010). Hispanic or Latino populations. Retrieved November 6, 2010, from http://www.cdc.gov/omhd/Populations/HL/HL.htm.

Cho, Y.T, Frisbie, W.P. \& Rogers, R.G. (2004). Nativity, duration of residence, and the health of Hispanic adults in the United States. International Migration Review, 38 (1), 184-211.

Collins, J.W. \& Shay, D.K (1994). Prevalence of low birth weight among Hispanic infants with United States-born and foreign-born mothers: the effect of urban poverty. American Journal of Epidemiology, 139, 184-192.

Finer, L.B. \& Henshaw, S. (2006). Disparities in rates of unintended pregnancy in the United States 19942001. Perspectives in Sexual and Reproductive Health, 38, 90-96.

Franco, M. (2011). Personal communication.

Frost, J.J., Singh, S. \& Finer, L.B. (2007). Factors associated with contraceptive use and nonuse, United States, 2004. Perspectives in Sexual and Reproductive Health, 39, 90-99.

Grossman, D., Fernandez, L., Hopkins, K., Amastae, J. \& Potter, J. (2010). Perceptions of the safety of oral contraceptives among a predominately Latina population in Texas. Contraception, 81, 254260.

Istre, G., McCoy, K., Womack, K., Fanning, L., Dekat, L. \& Stowe, M. (2002). Increasing the use of child restraints in motor vehicles in a Hispanic neighborhood. American Journal of Public Health, 92 (7), 1096-1099.

Kost, K., Singh, S., Vaughn, B., Trussell, J. \& Bankole, A. (2008). Estimates of contraceptive failure from 2002 National Survey of Family Growth. Contraception, 77, 10-21.

Landale N.S., Oropesa R.S. \& Gorman B.K. (2000). Migration and infant death: assimilation or selective migration among Puerto Ricans? American Sociological Review, 65, 888-909.

Lauritsen, J.M. \& Bruus M. Epidata (Version 3.1). A comprehensive tool for validated entry and documentation of data. The EpiData Association, Odense, Denmark, 2003-2005.

March of Dimes, (2004) Comenzando Bien. Education and Health Promotion, March of Dimes.

March of Dimes, (2011) Peristats. Retrieved May 28, 2011 from http://www.marchofdimes.com/peristats.

McDonald, J., Suellentrop, K., Paulozzi, L. \& Morrow, B. (2008). Reproductive health of the rapidly growing Hispanic population: Data from the Pregnancy Risk Assessment Monitoring System, 2002. Maternal Child Health Journal, 12, 343-356.

Meister, J.S., Warrick, L.H., de Zapién, J.G. \& Wood, A.H. (1992) Using Lay health workers: case study of a community based prenatal intervention. Journal of Community Health, 17 (1), 37-51.

Pew Hispanic Center (2011). Census 2010: 50 Million Latinos; Hispanics Account for More Than Half of Nation's Growth in Past Decade. Retrieved May 30, 2011 from http://pewhispanic.org/reports/report.php?ReportID=140.

Philipsen, N.C. (2004). Promoting and implementing evidence-based, best practices in childbirth education. Journal of Perinatal Education, 13 (3), 51-54.

Phillipi, J. (2009). Women's perceptions of access to prenatal care in the United States: A Literature Review. Journal of Midwifery and Women's Health, 54, 219-225.

Sable \& Herman (1997). The Relationship between prenatal health behavior advice and low birth weight. Public Health Reports, 112, 332-339.

SAS 9.2. SAS Institute Inc, Cary, NC. 2011

Smithwick-Leone, J. (2005). Looking at the present and towards the future: the perinatal outlook for Latina women and children in the midlands region of South Carolina. University of South Carolina. Columbia, South Carolina.

South Carolina Department of Health and Environmental Control (2009a). Burden of diabetes on South Carolina (2009 Ed.) Retrieved February 5, 2011 from http://www.scdhec.gov/administration/library/CR-009477.pdf.

South Carolina Department of Health and Environmental Control (2009b). South Carolina vital and morbidity statistics 2007. Retrieved February 3, 2011 from http://www.scdhec.gov/co/phsis/biostatistics/an_pubs/vms2007.pdf. 
South Carolina Department of Health and Environmental Control (2011). South Carolina minority population. Retrieved January 18, 2011 from http://www.scdhec.gov/health/minority/population.htm.

Spinelli, A., Baglio, G., Donati, S., Grandolfo, E. \& Osborn, J. (2003). Do antenatal classes benefit the mother and her baby? Journal of Maternal-Fetal and Neonatal Medicine, 13, 94-101.

United States Census Bureau. (2010). State and county quick facts. Retrieved December 14, 2010 from http://quickfacts.census.gov/qfd/index.html.

United States Department of Health and Human Services. (2010). Healthy People 2020. Retrieved May 31, 2011 from http://www.healthypeople.gov/2020/default.aspx.

Wasserman, M., Bender, D., \& Lee, S. (2007). Use of preventive maternal and child health services by Latina women. Medical Care Research and Review, 64 (1), 4-45.

Wieland, M.L., Weis, J.A., Palmer, T., Goodson, M., Loth, S., Omer, F., Abbenyi, A., Krucker, K., Edens, K., \& Sia, I.G. (2012). Physical activity and nutrition among immigrant and refugee women: A community-based participatory research approach. Women's Health Issues, 22 (2), e225-32.

World Health Organization (1978). Declaration of Alma-Ata. Retrieved February 5, 2011 from http://www.who.int/publications/almaata_declaration_en.pdf

\author{
Author Information \\ *Myriam E. Torres, PhD, MSPH \\ University of South Carolina \\ Department of Epidemiology/Biostatistics \\ 730 Devine Street, Suite 109, Columbia, SC 29208 \\ Phone: 803-777-2598 \\ Fax: (803) 251-0318 \\ E-mail: myriam.torres@sc.edu \\ Julie Smithwick, LMSW \\ University of South Carolina \\ Kathryn J. Luchok, PhD \\ University of South Carolina \\ Gwyn Rodman-Rice MPH, RN \\ University of South Carolina \\ * corresponding author
}

